2004-2013. The external causes of death were based on the International Classification of Diseases, the $10^{\text {th }}$ revision (ICD10) and the underlying cause of death was determined as Intentional self-harm (X60-X84, ICD-10). In the study a total number of suicide deaths was used as well as overall and specific mortality rates cross-classified by year, age and gender.

Results In period 2004-2013 there were 488 suicides in SDC (an average annual rate of 10.5 per 100,000 ), representing $1.3 \%$ of total male deaths and $0.6 \%$ of total female deaths. Suicide was the second or the third leading cause of injury death for all agesaccounting for one-fifth of all injury deaths in the observed period. As study results showed, males were two times likely to commit suicide than females. The suicide rate for males was 2.1 times higher than rate for females (14.2 versus 6.5 per 100,000$)$. Although suicide deaths affect almost all age groups, those aged $35-54$ had the highest rates. The suicide rates have declined in recent years, but the growing trend of suicide deaths in young males is concerning fact.

Conclusions Our study results can be used as a base for developing specific suicide prevention programs at regional level. Preventive strategies implemented at regional level identifying vulnerable population groups could be more effective than global strategies.

\section{AN EXPLORATION OF CHILDREN SUICIDES IN QUEENSLAND, AUSTRALIA. CONSIDERATIONS FOR PREVENTION, INTERVENTION AND POSTVENTION}

Bridie Scott-Parker, Florin Oprescu, Jeanne Dayton. University of the Sunshine Coast

\subsection{6/injuryprev-2016-042156.567}

Background Youth and child suicide prevention is a national and global priority. In Australia 35\% of all male deaths and $26 \%$ of all female deaths by suicide were in the 15-19 years old group. Analysis of available suicide data could inform policy and practice focused on prevention, early intervention and post intervention. Methods Deidentified child suicide data for the period 1 July 2004 to 30 June 2014 was analysed using Leximancer version 4 and SPSS Version 22. Variables analysed included gender, age, residence, child safety system records, method of suicide, mental health issues, child abuse and precipitating event among others.

Results Between 2004-2014, 159 children commited suicide. Three quarters were 15-17 years of age, with the youngest being 9 years of age. Two thirds were male. Compared to females, males were less likely to be known to the child safety system within the last 3 years before death $(p=0.097)$, have known mental health of behavioural issues $(p=0.032)$, show previous suicidal thoughts $(p=0.014)$ or attempts $(p=0.001)$ or selfharm $(p<0.001)$, or have a history of child abuse $(p=0.009)$. Forty five percent were from very low or low socio-economic areas. Hanging was the most frequent method of suicide and was associated with precipitating arguments. Non-hanging deaths were more likely in metropolitan and outer regional areas, in families with a history of mental illness and in cases with a history of physical abuse. Evidence of planning was present in over half of the cases.

Conclusion Better understanding of characteristics of suicides is important for early detection and prevention. Indicators of planning need to be identified and documented in order to empower communities to take action that protects the children. Multi-level interventions that address the child, the family, the community and health services integration are necessary for both pre and post suicide periods.

\section{Violence}

\section{Post Mon 1.15}

\section{PROACTIVE COMMUNITY-POLICING RESPONSES TO DOMESTIC AND INTIMATE PARTNER VIOLENCE (D/IPV) IN CANADA}

${ }^{1}$ Carmen Gill, ${ }^{2}$ Leanne Fitch. ${ }^{1}$ University of New Brunswick, Canada; ${ }^{2}$ Fredericton Police Force, Canada

\subsection{6/injuryprev-2016-042156.568}

Background The Canadian Observatory on the Justice System's Response to Intimate Partner Violence (IPV) is an international network of academics, governments, and community-based organisation providing enhanced understanding of how justice responses to IPV operate. Since 2007 the Canadian Observatory conducted policy reviews; engaged governments in dialogue to share data collection strategies and facilitate research collaborations; and developed mechanisms to mobilise knowledge. In 2012, the Canadian Observatory initiated a reflection on police intervention in IPV situations that led to create a national dialogue on police practices and to provide evidence-based research on police response to IPV. In this perspective a national think tank was held in June 2014 with 35 ranking police from across Canada to discuss best practices implemented in different Canadian communities in regards to intimate partner violence. The event led to the creation of a working group of experts that is developing a national framework on police proaction and intervention to D/IPV.

Description In June 2015, the group of experts comprised of researchers, communities and police agencies met to determine the different steps for the development of a national framework. The creation of a national framework will provide: A foundation for consistent language, standards and policy for Canadian Police Agencies, to guide police proaction and intervention on D/IPV; Resources for collaborative education, prevention, intervention, and supports for victims, abusers and communities; The creation of visual and narrative reference model on proactive D/IPV response to be used by all Canadian police. The group of experts is to complete their work by the end of March 2016.

Results The development of a national framework encompasses a dialogue with police forces, communities and academics, including working sessions with the group of experts, consultations with community stakeholders, police forces and other professionals involved in the area of D/IPV intervention. In this presentation, we will discuss the process that led to the development of a national framework on Proactive Community-Policing Responses to D/IPV in Canada and how such process led to a supported dialogue among police agencies on the issue.

\section{THE ROLE OF ONE-STOP CRISIS MANAGEMENT CENTRES (OCMCS) IN VIOLENCE PREVENTION}

Rekha Rana. Nepal Health Sector Support Program, Ministry of Health and Population (MHP) Nepal

10.1136/injuryprev-2016-042156.569 